\title{
Giant soft tissue liposarcoma of chest wall
}

\author{
Y. Altemur Karamustafaoğlu, MD, and Ahmet Güngör, MD, Kirikkale, Turkey
}

$\mathrm{P}$ rimary soft tissue sarcomas of the chest wall are uncommon, and data concerning treatment and results are sparse. Two thirds of the patients are older than 40 years. Complete surgical excision is the preferred treatment when possible. Subtotal resection is of short-term, palliative ben-

From the Department of Thoracic Surgery, Kirikkale State Hospital, Kirikkale, Turkey.

Received for publication June 28, 2004; revisions received Aug 14, 2004; accepted for publication Aug 20, 2004.

Address for reprints: Y. Altemur Karamustafaoğlu, MD, Yaylacik mah. 61 sok No:1 Daire:11 Halil Çetin apartmani, 71100 Kirikkale, Turkey (E-mail: altemurk@hotmail.com).

J Thorac Cardiovasc Surg 2005;129:1189-90

$0022-5223 / \$ 30.00$

Copyright () 2005 by The American Association for Thoracic Surgery doi:10.1016/j.jtcvs.2004.08.055
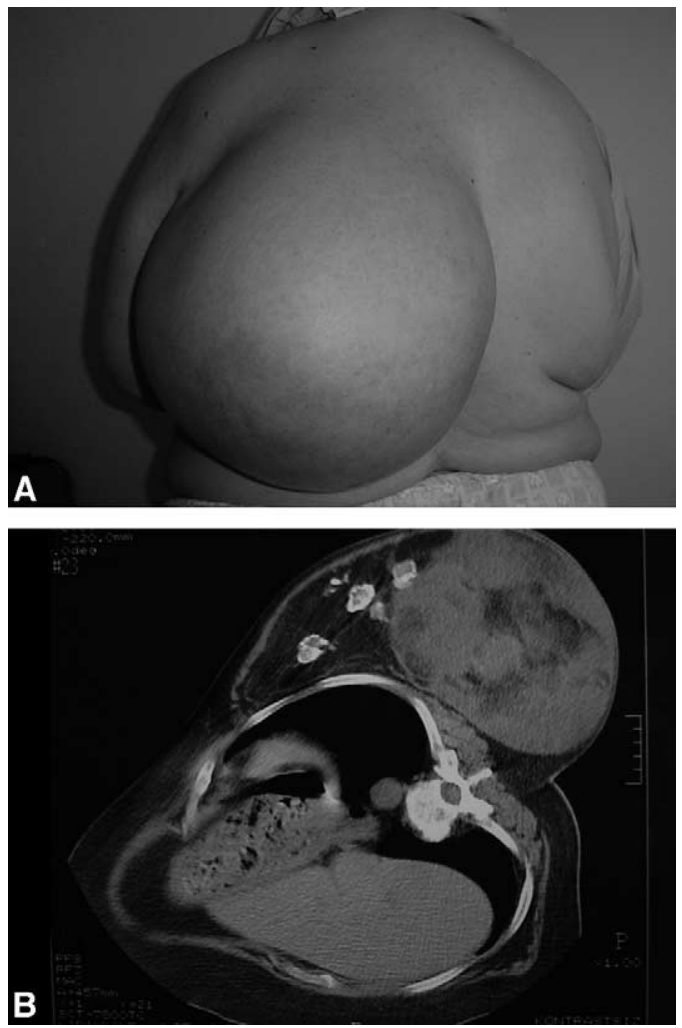

Figure 1. A, Photograph showing a huge mass in the patient's back. B, Computed tomographic scan showing a large fatty mass having a solid density and including calcifications in the posterior left hemithorax. efit only. Radiation therapy can be used palliatively for early recurrence. Survival of patients with primary soft tissue sarcomas of the chest wall after resection is similar to that of patients with sarcomas of the extremities. ${ }^{1}$

\section{Clinical Summary}

A 73-year-old woman presented with a 25-year history of an enlarging, painless, huge mass in the back (Figure 1, A). She visited our hospital on December 8, 2003. A well-defined abnormal shadow was seen in the middle and lower fields of the left hemithorax on the chest x-ray film. Computed tomography showed a large fatty mass having a solid density and including calcifications in the posterior left hemithorax (Figure 1, B). She was treated by a wide, local, complete excision that excluded the ribs and was covered with a partially prolonged latissimus dorsi flap. Histologic diagnosis was reported as a well-differentiated liposarcoma $33 \times$ $30 \times 17 \mathrm{~cm}$ in size. She was referred for radiotheraphy after the resection for prevention of early recurrence (Figure 2).

\section{Discussion}

Liposarcomas most often originate in the extremities and on the retroperitoneum, less frequently in the head and neck, and rarely in the thorax. Liposarcoma accounts for $15 \%$ of primary chest wall soft tissue sarcomas. ${ }^{1}$ There is an equal incidence in men and women. Schweitzer and Aguam $^{2}$ reported that $85 \%$ of patients

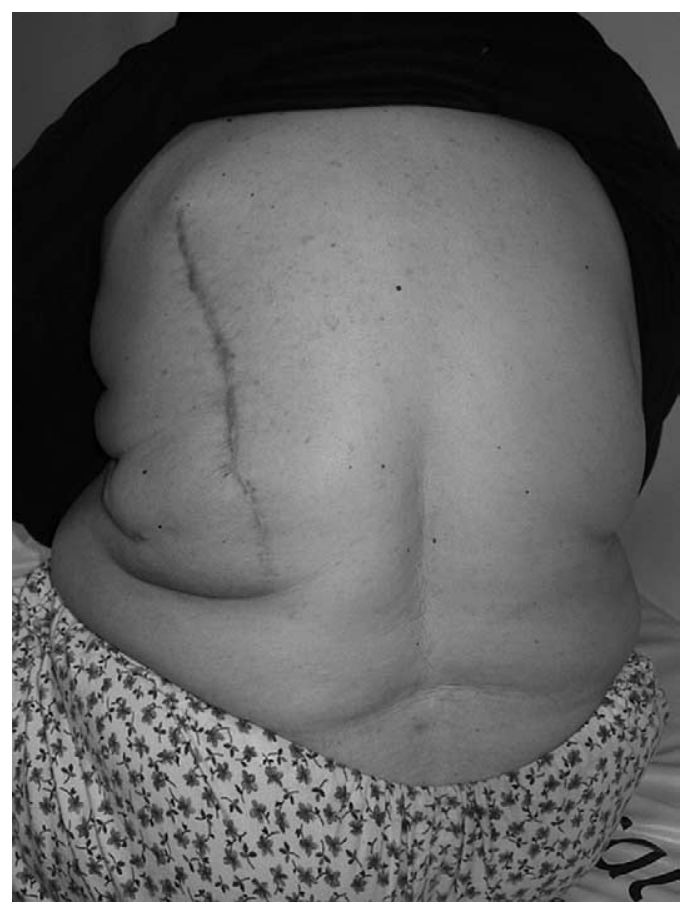

Figure 2. Cosmetic result on postoperative day 10. 
with a liposarcoma are symptomatic and that $15 \%$ have an asymptomatic liposarcoma discovered on a routine chest radiograph. Liposarcomas are usually large. The cases reported by Klimstra and associates ${ }^{3}$ ranged from 6 to $40 \mathrm{~cm}$, with a mean weight of 1500 g. Enzinger and Weiss ${ }^{4}$ divided liposarcomas into the following 5 major morphologic subtypes: well differentiated, myxoid, round cell, dedifferentiated, and pleomorphic. Myxoid liposarcomas account for $40 \%$ to $50 \%$ of these tumors. Welldifferentiated liposarcomas are a less-aggressive neoplasm and can produce metastases. Complete surgical excision is the preferred therapeutic choice. Recurrence can occur in a subtotal resection despite adjuvant therapy. The pseudoencapsulated lesions that can be completely removed have a better prognosis than the noncapsulated and less well-differentiated tumors; however, most primary chest wall soft tissue sarcomas (70\%) are low grade. Local recurrence was reported in $33 \%$ of patients in the study by Greager and colleagues. ${ }^{5}$ The presence of local recurrence has no significant effect on the overall survival. ${ }^{1}$ Radiotherapy may be effective in the control of local recurrence, but its role is unclear.

\section{References}

1. Gordon MS, Hajdu SE, Bains MS, Burt ME. Soft tissue sarcomas of the chest wall. J Thorac Cardiovasc Surg. 1991;101:843-54.

2. Schweitzer DL, Aguam AS. Primary liposarcoma of the mediastinum. Report of a case and review of the literature. J Thorac Cardiovasc Surg. 1977;74:83-97.

3. Klimstra DS, Moran CA, Perino G, Koss MN, Rosai J. Liposarcoma of the anterior mediastinum and thymus: a clinicopathologic study of 28 cases. Am J Surg Pathol. 1995;19:782-91.

4. Enzinger FM, Weiss SW. Soft tissue tumors. 3rd ed. St Louis: CV Mosby; 1995, p. 431.

5. Greager JA, Patel MK, Briele HA, Walker MJ, Wood DK, Gupta TK. Soft tisue sarcomas of the adult thoracic wall. Cancer. 1987;59:370-3.

\section{Cerebral malperfusion in acute type $A$ dissection: Direct innominate artery cannulation}

Genichi Sakaguchi, MD, PhD, Tatsuhiko Komiya, MD, Nobushige Tamura, MD, PhD, Shogo Obata, MD, Shinji Masuyama, MD, Chieri Kimura, MD, and Taira Kobayashi, MD, Okayama, Japan

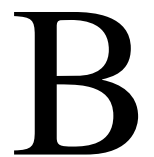

rain ischemia caused by malperfusion of major arch vessels in acute type A dissection is associated with a significantly higher risk of mortality. This report describes an urgent introduction of the selective cerebral perfusion immediately after establishment of cardiopulmonary bypass followed by total arch replacement in a case of acute type A dissection complicated with preoperative cerebral ischemia.

\section{Clinical Summary}

A 56-year-old man was transferred to our hospital after presenting with an abrupt loss of consciousness. At the time of admission, the patient was lethargic, although easily arousable, and responded to his name being called. His consciousness

\footnotetext{
From the Department of Cardiovascular Surgery, Kurashiki Central Hospital, Okayama, Japan.

Received for publication Aug 6, 2004; revisions received Sept 1, 2004; accepted for publication Sept 3, 2004.

Address for reprints: Genichi Sakaguchi, MD, Department of Cardiovascular Surgery, Kurashiki Central Hospital, Miwa, Kurashiki City, Okayama, 710-8602, Japan (E-mail: gs8722@kchnet.or.jp).

J Thorac Cardiovasc Surg 2005;129:1190-1

$0022-5223 / \$ 30.00$

Copyright (C) 2005 by The American Association for Thoracic Surgery

doi:10.1016/j.jtcvs.2004.09.036
}

level was assessed at 14 on the Glasgow Coma Scale. His initial brain

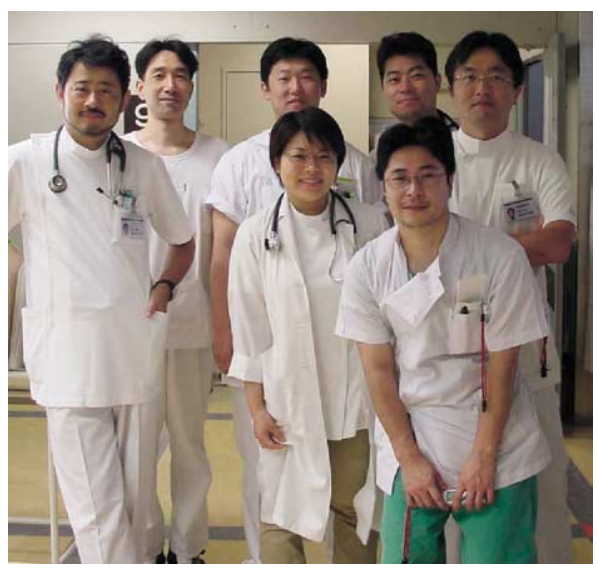

Komiya, Tamura, Masuyama, Kimura, Kobayashi, Obata, Sakaguchi (left to right) computed to-

mographic (CT)

scan disclosed neither acute hemorrhage nor obvious ischemic changes. According to the neurologic status and CT findings, it was speculated that he did not have a cerebral infarction, despite the right-sided hemispheric hypoperfusion.

Duplex ultrasonography showed compression of the true lumen by the false lumen in the right carotid artery (Figure 1). A contrastenhanced CT scan revealed a type A dissection extending from the sinotubular junction down to the bilateral common iliac arteries.

An emergency operation was performed 2 hours after admission. Near-infrared optical spectrophotometer probes were attached to the bilateral forehead of the patient to monitor regional cerebral oxygenation $\left(\mathrm{rSO}_{2}\right)$ throughout the operation (Figure 2). $\mathrm{rSO}_{2}$ in the right side of the forehead was $21 \%$, and that in the left side of the forehead was $50 \%$.

After cardiopulmonary bypass was established with the right femoral artery used for inflow and the superior and inferior venae cavae for drainage, $\mathrm{rSO}_{2}$ was still at a critically low level on the right side. The innominate artery was crossclamped proximally and transected. A $14 \mathrm{~F}$ perfusion catheter was inserted in the true 